NOTICE: This is the author's version of a work that was accepted for publication in Talanta. Changes resulting from the publishing process, such as peer review, editing, corrections, structural formatting, and other quality control mechanisms may not be reflected in this document. Changes may have been made to this work since it was submitted for publication. A definitive version was subsequently published in Talanta, Vol. 132 (2015). http://doi.org/10.1016/j.talanta.2014.08.060 


\section{Electrochemical Detection of Ractopamine at Arrays of Micro-Liquid | Liquid Interfaces}

Masniza Sairi ${ }^{\mathrm{a}, \mathrm{b}}$ and Damien W. M. Arrigan ${ }^{\mathrm{a}, *}$

a Nanochemistry Research Institute, Department of Chemistry, Curtin University, GPO Box U1987, Perth, Western Australia 6845, Australia

${ }^{\mathrm{b}}$ Mechanization and Automation Research Centre, Malaysian Agricultural Research and Development Institute (MARDI), P.O. Box 12301, 50774 Kuala Lumpur, Malaysia

"Corresponding author. Tel.: +61-8-9266-9734; Fax: +61-8-9266-2300; E-mail:

D.Arrigan@curtin.edu.au

\section{Abstract}

The behaviour of protonated ractopamine $\left(\mathrm{RacH}^{+}\right)$at an array of micro-interfaces between two immiscible electrolyte solutions (micro-ITIES) was investigated via cyclic voltammetry (CV) and linear sweep stripping voltammetry (LSSV). The micro-ITIES array was formed at silicon membranes containing 30 pores of radius $11.09 \pm 0.12 \mu \mathrm{m}$ and pore centre-to-centre separation of $18.4 \pm 2.1$ times the pore radius. $\mathrm{CV}$ shows that $\mathrm{RaCH}^{+}$transferred across the water $\mid 1,6$ dichlorohexane $\mu$ ITIES array at a very positive applied potential, close to the upper limit of the potential window. Nevertheless, CV was used in the estimation of some of the drug's thermodynamic parameters, such as the formal transfer potential and the Gibbs transfer energy. LSSV was implemented by pre-concentration of the drug, into the organic phase, followed by voltammetric detection, based on the back-transfer of $\mathrm{RacH}^{+}$from the organic to aqueous phase. Under optimised pre-concentration and detection conditions, a limit of detection of 0.1 $\mu \mathrm{M}$ was achieved. In addition, the impact of substances such as sugar, ascorbic acid, metal ions, amino acid and urea on $\mathrm{RacH}^{+}$detection was assessed. The detection of $\mathrm{RacH}^{+}$in artificial serum indicated that the presence of serum protein interferes in the detection signal, so that sample deproteinisation is required for feasible bioanalytical applications.

Keywords: ractopamine, ion transfer, micro-ITIES, voltammetry, stripping voltammetry 


\section{Introduction}

Ion transfer across the interface between two immiscible electrolyte solutions (ITIES) [1-4] has received increasing interest in the field of electrochemistry, liquid | liquid extraction and membrane transport. Electrochemistry at liquid | liquid interfaces has moved from the transfer of model ions such as tetraalkylammonium ions to the detection of molecules of biological importance such as proteins, peptides, amino acids, drugs, neurotransmitters, food additives and DNA [5]. Thus it plays a potentially important role in new bioanalytical methods.

Ractopamine (Rac) (Fig. 1(a)) is a phenyl $\beta$-ethanolamine, with $\beta$-adrenergic agonist properties [6-9]. It is primarily used as a therapeutic drug for treatment of pulmonary diseases such as asthma in human and veterinary medicine $[6,7]$. Unfortunately, this substance is also illegally applied in the livestock industry as a nutrient repartitioning agent. Research shows that $\beta$-agonists divert fat deposition to the production of muscle tissues by increasing nitrogen retention, protein synthesis and lipolysis [6, 7, 9-11]. It also improves growth rate and feed conversion when fed to livestock (such as calves, poultry etc.) [8, 9, 12]. Recently, veterinary drug residues have become a public food safety concern where ractopamine-treated animals may pose adverse effects on human health, especially in the cardiovascular and central nervous systems $[6,7,9,12,13]$. Thus, it is banned in many countries, including within the European Union and China, although it is approved by the United States' Food and Drug Administration (U.S. FDA) [12, 14-16]. As a result, rapid, simple and sensitive analytical methods for the detection of ractopamine residues are required.

To date, various analytical methods have been reported for the detection of ractopamine, such as immunoassays $[9,10,17]$, electrochemical methods $[6,7,13,16]$, gas chromatography-mass spectrometry [11], liquid chromatography tandem mass spectrometry $[12,18]$ and high performance liquid chromatography $[8,14,15]$. Electrochemical methods offer the advantages of low instrumental cost and fast analysis, and thus may be the preferred methods in ractopamine detection [7]. Despite the fact that many electrochemical methods have been developed, those studies focused on solid | liquid interfaces, using primarily cyclic voltammetry (CV) $[6,7,16]$. The two phenolic groups in ractopamine are easily oxidised $[6,7$, 13]. Differential pulse voltammetry (DPV) has also been employed for the detection of ractopamine $[6,7,13]$.

To the best of our knowledge, no studies have been reported on the electrochemical detection of ionised ractopamine based on transfer across the ITIES. Thus, this study opens up the possibilities for the detection of ractopamine based on charge transfer across micro-ITIES. 
However, the detection of other drugs at the ITIES via various electrochemical methods has been reported in the literature, namely the anticancer drug daunorubicin at a microporous polyethylene terephthalate (PET) membrane-supported ITIES [19], catamphiphilic drugs at a solvent polymeric membrane [20], and $\beta$-blocker drugs (propranolol, timolol and sotalol) at a microporous silicon membrane-supported ITIES [21]. Besides analytical studies, the ability of the ITIES to mimic the drug transfer across biological membranes has offered insight into mechanisms of drug action [19]. Voltammetry at the ITIES has been used to investigate the transfer characteristics of charged drug molecules, for example, the Galvani potential difference $\left(\Delta_{o}^{w} \emptyset\right)$ for the ion transfer and the Gibbs energy of transfer, which is directly related [22]. Previous studies by Girault and co-workers [23, 24] have shown that the ITIES is a suitable platform for the determination of the partition coefficient of the ionised species, which in turn defines the drug's lipophilicity in biological systems [19, 20, 22].

Direct drug detection in physiological matrices, such as blood and blood-derived samples, is important because it offers information regarding circulating levels. Yet, this can be hindered due to drug-protein binding [25]. The drug-protein interaction in blood plays an important role in determining drug transportation, absorption, distribution, metabolism and excretion [26-28]. Serum albumins are present at the highest abundance in blood (ca. $60 \%$ of the total albumin) [29, 30], and these proteins exhibit high affinity towards drugs [26-28, 31]. In addition, the pharmacological activity of drugs relates to their free concentration in blood [25]. The measurement of drug-protein interactions has seen the emergence of a number of novel labelfree strategies [32]. In this study, albumin from bovine serum (BSA) is employed due to the fact that human and bovine serum albumins are homologous proteins [29, 33, 34]. BSA is a highly water-soluble globular protein, which has a molar mass of 69,000 amu and a hydrodynamic radius of ca. $3.25 \mathrm{~nm}[25,35]$. BSA also has a low isoelectric point (pI of 5.4) and high negative net charge at neutral $\mathrm{pH}$ [36].

In this report, emphasis is placed on the electrochemical behaviour of protonated ractopamine $\left(\mathrm{RacH}^{+}\right)$at the micro-ITIES array. Quantitative methods that involve the detection of $\mathrm{RaCH}^{+}$by simple ion transfer at the water 1 ,6-dichlorohexane $(\mathrm{DCH})$ micro-interface array are presented, using CV and linear sweep stripping voltammetry (LSSV). Stripping analysis at micro-liquid | liquid interface arrays is appropriate for analyte detection in media such as biological fluids, soil extracts and water [37], thus this technique is examined in this study. The thermodynamic parameters for the transfer of ionisable ractopamine are discussed. In addition to the analytical parameters, the influence of the interfering substances, including serum protein, towards $\mathrm{RacH}^{+}$detection are also reported. 


\section{Materials and methods}

\subsection{Reagents}

All reagents used were purchased from Sigma-Aldrich Pty. Ltd., Australia and used without further purification, unless stated otherwise. D-Glucose and sodium chloride ( $\mathrm{NaCl})$ were purchased from Ajax Finechem Pty. Ltd., Australia, L-ascorbic acid and potassium phosphate monobasic $\left(\mathrm{KH}_{2} \mathrm{PO}_{4}\right)$ from BDH Laboratory Supplies, Australia, and sodium sulfate $\left(\mathrm{Na}_{2} \mathrm{SO}_{4}\right)$ from Chem-Supply Pty. Ltd, Australia.

The aqueous phase solution of $10 \mathrm{mM}$ lithium chloride ( $\mathrm{LiCl}$ ) was prepared in ultrapure water (resistivity of $18 \mathrm{M} \Omega \mathrm{cm}$ ) from a Milli-Q water purification system (Millipore Pty. Ltd., North Ryde, NSW, Australia). The organic electrolyte salt was prepared by metathesis of bis(triphenylphosphoranylidene)ammonium chloride (BTPPACl) and potassium tetrakis(4chlorophenyl)borate (KTPBCl). The organic phase was mechanically stabilized as a polymer gel [38-41] and was composed of the supporting electrolyte (10 mM BTPPATPBCI) and low molecular weight poly(vinylchloride) (PVC) $(10 \% \mathrm{w} / \mathrm{v})$, dissolved in 1,6-dichlorohexane. Prior to the experiments, both the aqueous and organic phase solvents were mutually pre-saturated. The organic reference solution consisted of $10 \mathrm{mM} \mathrm{BTPPACl}$ dissolved in $10 \mathrm{mM} \mathrm{LiCl}$ (aqueous). Ractopamine hydrochloride and tetrapropylammonium chloride (TPrACI) served as the drug and model analyte species studied, respectively. A stock solution of TPrACI was prepared in $10 \mathrm{mM} \mathrm{LiCl}$ while the stock solution of ractopamine hydrochloride was prepared in methanol $(\mathrm{MeOH})$ due to its low solubility in water [15].

In the interfering substances study, the interferents were prepared in $1 \mathrm{mM}$ PBS solution as the supporting electrolyte, which contained $1 \mathrm{mM}$ phosphate buffer, $0.27 \mathrm{mM}$ potassium chloride (KCl) and $13.7 \mathrm{mM} \mathrm{NaCl}$. D-Glucose, L-ascorbic acid, $\mathrm{KCl}, \mathrm{NaCl}, \mathrm{Na}_{2} \mathrm{SO}_{4}$, glycine and urea were the interfering substances studied, and the concentration of each of these was fixed at $5.0 \mathrm{mM}$. The effect of artificial serum matrix $[25,42,43]$ on the detection of $\mathrm{RacH}^{+}$was also investigated. The artificial serum used was composed of $1.5 \mathrm{mM} \mathrm{KCl}, 5.0 \mathrm{mM}$ calcium chloride $\left(\mathrm{CaCl}_{2}\right), 1.6 \mathrm{mM}$ magnesium chloride $\left(\mathrm{MgCl}_{2}\right), 4.7 \mathrm{mM}$ D-glucose, $1.0 \mathrm{mM}$ sodium phosphate monobasic $\left(\mathrm{NaH}_{2} \mathrm{PO}_{4}\right), 1.0 \mathrm{mM} \mathrm{KH} \mathrm{PO}_{4}, 2.5 \mathrm{mM}$ urea and $0.6 \mathrm{mM}$ bovine serum albumin, prepared in ultrapure water. 


\subsection{Preparation of micro-interface arrays}

The micropore arrays used for micro-ITIES patterning were fabricated in $100 \mu \mathrm{m}$ thick silicon membrane by lithographic patterning and wet and dry silicon etching methods at Tyndall National Institute, University College Cork, Cork, Ireland [41]. The micropores are depicted in Fig. 1 (b) and (c), with $11.09 \pm 0.12 \mu \mathrm{m}$ radius, $r_{a}, 30$ pores in a hexagonal close-packed arrangement, and with pore centre-to-centre separation, $r_{c}$, of $18.4 \pm 2.1$ times the pore radius, $r_{a}$ (i.e. $\left.r_{c}=18.4 r_{a}\right)$. The silicon chip $(5 \mathrm{~mm} \times 5 \mathrm{~mm})$ was sealed onto the lower orifice of a cylindrical glass tube $\left(d_{\text {inner }}=2.5 \mathrm{~mm}, d_{\text {outer }}=4.0 \mathrm{~mm}\right)$ using silicone rubber sealant (Selleys, Australia and New Zealand) and allowed to cure for 72 hours before use. The membrane was cleaned with acetone and dried in air before and after each electrochemical experiment. All the experiments were conducted at room temperature $\left(20^{\circ} \mathrm{C}\right)$.

\subsection{Experimental procedure at the micro-ITIES array}

The electrochemical techniques were performed using an Autolab PGSTAT 302N (Metrohm, The Netherlands) together with the Nova 1.7 or Nova 1.8 software supplied with the instrument. The electrochemical cell was housed in a Faraday cage for the duration of the experiment to minimize electrical noise. A two-electrode electrochemical cell was employed in this study since the IR drop effect at micro-ITIES system is not too high as compared to macro-ITIES system [44]. Both $\mathrm{Ag} \mid \mathrm{AgCl}$ electrodes served as reference and counter electrodes in either phase. The applied potential, $E$, is defined as the potential difference between the two electrodes, with positive current due to the transfer of cations from the aqueous to the organic phase [20].

The borosilicate glass tube with membrane sealed to one end with silicone sealant contained $100 \mu \mathrm{L}$ of the gellified-organic phase and $200 \mu \mathrm{L}$ of the organic reference solution. This was then immersed in $6 \mathrm{~mL}$ of the aqueous phase solution in a $10 \mathrm{~mL}$ glass beaker. The electrochemical cells employed in this study can be schematically summarized as follows:

$\mathrm{Ag}|\mathrm{AgCl}| \times \mathrm{M}$ ractopamine $\mathrm{HCl}+10 \mathrm{mM} \mathrm{LiCl}_{\mathrm{W}}|| 10 \mathrm{mM}$ Cell 1 BTPPATPBCl $_{\text {DCH }} \mid 10 \mathrm{mM} \mathrm{BTPPACl}$ in $10 \mathrm{mM} \mathrm{LiCl}|\mathrm{AgCl}| \mathrm{Ag}$

$\mathrm{Ag}|\mathrm{AgCl}| 0.1 \mathrm{mM}$ ractopamineHCl $+5 \mathrm{mM}$ interfering substance $+10 \mathrm{mM} \quad$ Cell 2 $\mathrm{LiCl}_{W}|| 10 \mathrm{mM}$ BTPPATPBCl $\mathrm{DCH}_{\mathrm{CH}} \mid 10 \mathrm{mM}$ BTPPACl in $10 \mathrm{mM}$ $\mathrm{LiCl}_{\mathrm{W}}|\mathrm{AgCl}| \mathrm{Ag}$ 
$\mathrm{Ag}|\mathrm{AgCl}| \times \mathrm{M}$ ractopamine $\mathrm{HCl}+$ artificial serum $\mathrm{W}|| 10 \mathrm{mM}$

BTPPATPBCl $_{D C H} \mid 10 \mathrm{mM} \mathrm{BTPPACl}$ in $10 \mathrm{mM} \mathrm{LiCl}_{W}|\mathrm{AgCl}| \mathrm{Ag}$

where $\mathrm{x}$ is the concentration of ractopamine in the aqueous phase. In every electrochemical cell, $\operatorname{TPrA}{ }^{+}$was spiked into the aqueous phase after the final $\mathrm{RacH}^{+}$or interferent injection, as a control of the potential axis.

Prior to the injection of analyte into the aqueous phase with a micropipette to achieve the required concentration, a background $\mathrm{CV}$ at $5 \mathrm{mV} \mathrm{s}^{-1}$ was recorded over a wide potential range so as to establish the limits of the available potential window. A quiet time of $5 \mathrm{~s}$ at the initial potential of each scan was implemented. In LSSV, the parameters pre-concentration potential, pre-concentration time and sweep rate were explored to determine the optimum values, and these were implemented in subsequent experiments.

\section{Results and discussion}

\section{1. $C V$ at the micro-ITIES array}

CV profiles of 20 to $100 \mu \mathrm{M} \mathrm{RacH}^{+}$at the gelled micro-ITIES arrays (Cell 1) are presented in Fig. 2 (a) and (b), in the form of experimental data and background-subtracted voltammograms, respectively. The $\mathrm{p} K_{a}$ of the amine group in ractopamine is 9.4 [8], so that in the aqueous phase used in this work, $10 \mathrm{mM} \mathrm{LiCl}(\mathrm{pH} \sim 6)[19,21]$, the drug is cationic. The CVs show that $\mathrm{RacH}^{+}$ ions, which are initially present in the aqueous phase, are transferred into the gelled organic phase under potential control, on the forward CV sweep. These ions are transferred back from the organic into the aqueous phase, during the reverse scan.

The shape and magnitude of the voltammetric response are highly dependent on factors such as the diffusion regime shape, the position of the ITIES within the pores, the properties of the electrolyte solutions and of the transferring ion species, and the magnitude of the diffusion zone extension $(\delta)[45,46]$. The interfaces employed here were inlaid so that each pore was filled with the organic electrolyte solution and the interface was at the aqueous side of the membrane [45]. Generally, for an inlaid micro-ITIES array, steady-state voltammograms are obtained in the forward CV sweep, indicating establishment of radial diffusion fields, while peakshaped voltammograms are obtained on the reverse scans, attributed to linear diffusion control.

However, in this study, the CVs on the forward scan show that the foot of the ion transfer wave was at a very positive applied potential difference $(0.8 \mathrm{~V})$, close to the upper limit of 
potential window (Fig. 2(a)). The current increased steadily with applied potential up to the switching potential, so that a fully-develop stead-state wave shape was not obtained. On the reverse scan, a peak-shaped feature was observed, due to the transfer of $\mathrm{RacH}^{+}$ions which had been retained within the micropores. The incorporation of PVC in the organic phase increases the viscosity, and hence slows down rate of diffusion of ions in the organogel [45], so that the diffusion coefficient of a target analyte in the gelled organic phase may be ca. ninetimes lower than in the aqueous phase [45].

The background-subtracted currents on the forward and reverse scans (Fig. 2(b)) increased linearly with $\mathrm{RacH}^{+}$concentration in the aqueous phase, with the maximum currents chosen to construct the calibration graphs of the forward scan (Fig. 2 (c)). Theoretically, the current of the forward scan can be modelled by the Saito equation [47, 48] if a steady-state current (radial diffusion control) had been achieved. At the ITIES, the potential window is restricted by the transfer of background electrolyte ions [5]. However, in this study it was found that $\mathrm{RacH}^{+}$ transfer occurred at a potential just below the transfer of the background electrolytes and steady-state current for $\mathrm{RacH}^{+}$transfer was not achieved.

Following the final $\mathrm{RacH}^{+}$experiment, $100 \mu \mathrm{M} \mathrm{TPrA}^{+}$was spiked into the aqueous phase (Fig. 2 (a) inset - top, and (b) inset) as a model ion and a potential axis reference ion [19, 49]. The resulting CV showed a steady-state behaviour on the forward scan, while the reverse scan demonstrated a peak shape, in agreement with previous experiments and computer simulations [45]. This micro-ITIES array thus displayed the expected mass-transport behaviour. The foot of the ion transfer wave, and the half-wave potential were observed at approximately $0.45 \mathrm{~V}$ and $0.52 \mathrm{~V}$, respectively, in agreement with previous studies [25, 48]. The formula to calculate the steady-state current (limiting current) for ion transferring from the aqueous to the organic phase is given by the Saito equation modified for the number of micropores in the membrane [47]:

$I_{s S}=4 z F D C r_{a} N_{p}$

where $I_{s S}$ is the steady-state current, $z, D$ and $C$ are the charge, diffusion coefficient and bulk concentration, of the transferring ions in the aqueous phase, correspondingly. $F$ is the Faraday constant $\left(96,487 \mathrm{C} \mathrm{mol}^{-1}\right)$ and $N_{p}$ is the number of micropores. The steady-state experimental current was within ca. $10 \%$ of the current obtained from Eq. (1). This may indicate that the interfaces formed at the micropore mouths were not flat, in turn enhancing the radial diffusion to the interfaces so that the current is increased. The steady-state current for radial diffusion to an array of hemispherical micro-ITIES is given by [50, 51]:

$I_{s s}=2 \pi z F D C r_{a} N_{p}$ 
However, in this case the experimental current was ca. $30 \%$ lower than that calculated from Eq. (2). This indicates that the $\mu$ ITIES were closest to inlaid microinterface behaviour.

There is a lack of information in the literature on the diffusion coefficient of ractopamine. Attempts to determine this from the oxidation response at glassy carbon electrode were not successful, due to the problems associated with fouling of the surface, probably by the adsorption of either the drug or its oxidation products. A similar fouling problem was reported previously for salbutamol oxidation at glassy carbon electrodes [52]. Therefore, an assumption of the diffusion coefficient value was made based on the published data for salbutamol sulfate $\left(D=3.3 \times 10^{-6} \mathrm{~cm}^{2} \mathrm{~s}^{-1}\right)$ [53], since ractopamine and salbutamol are a group of $\beta$-adrenergic agonist which possess similar chemical structures and functions [16]. Use of this value in Eq. (1) produced a steady-state current for the transfer of $\mathrm{RacH}^{+}$across microlTIES array that was lower than the maximum current in the forward scan, suggesting the need for an accurate diffusion coefficient value.

A final control experiment was the impact of methanol on the $\mathrm{CV}$, because the ractopamine stock solution was prepared in $\mathrm{MeOH}$ (see lower inset in Fig. 2 (a)). The same injection volume used to prepare 20 to $100 \mu \mathrm{M}$ of analyte was applied. It was observed that the addition of $\mathrm{MeOH}$ had no observable effect on the analyte CV.

\subsection{Thermodynamic parameters of $\mathrm{RaCH}^{+}$transfer at the water / DCH interface}

A number of thermodynamic parameters for the drug transfer were determined from the CV data. These are listed in Table 1.

The value of the formal transfer potential of an ionised drug is obtained by transposing the measured experimental value to the Galvani potential scale, as given by the following expression [54-58]:

$E_{1 / 2}($ drug $)-\Delta_{o}^{w} \emptyset^{0^{\prime}}($ drug $)=E_{1 / 2}\left(\operatorname{TPrA}^{+}\right)-\Delta_{o}^{w} \emptyset^{0^{\prime}}\left(\operatorname{TPrA}^{+}\right)$

where $\Delta_{o}^{w} \emptyset^{0^{\prime}}\left(\operatorname{TPrA}^{+}\right)$is the formal transfer potential of the $\operatorname{TPrA}^{+}$ion. $E_{1 / 2}$ (drug) and $E_{1 / 2}\left(\operatorname{TPrA}^{+}\right)$are the experimental half-wave potentials of the drug and $\operatorname{TPrA}^{+}$transfer, respectively. In this study, a value of $-0.086 \vee$ was used for $\Delta_{o}^{w} \emptyset^{0^{\prime}}\left(\operatorname{TPrA}^{+}\right)[59]$. $\operatorname{TPr} A^{+}$ion was selected as a model ion since the transfer potential differs from that of $\mathrm{RacH}^{+}$and there is no mutual interference.

The Gibbs energy of transfer is directly related to the formal transfer potential of the ion transfer [60]. The ability to measure this value depends on the condition that the transferring ion 
has a lower magnitude of the Gibbs transfer energy than the ions of the supporting electrolytes $[58,61]$. However, for $\mathrm{RacH}^{+}$, the ion of interest transfers at the upper limit of the potential window so that the experimental measurement of the half-wave potential $\left(E_{1 / 2}(\mathrm{drug})\right)$ was not possible. A similar observation was reported by Osborne and Girault [58] for the transfer of ammonium ions across a water | 1,2-dichloroethane (DCE) interface and by Cacote et al. [62] for the direct transfer of $\mathrm{Ag}^{+}$ions across a water | DCE interface. A method to determine the $E_{1 / 2}$ of the species limiting the potential window was developed by Shao et al. [61], which was based on a set of simulated CVs in which the switching potential is set prior to the forward peak potential. The half-wave potential of the species limiting the potential window was then determined from the resultant working curve, which was a plot of $I_{e o s} / I_{r p}$ versus $E_{r p}-E_{1 / 2}$, where $I_{e o s}$ and $I_{r p}$ are the current at the end of the forward scan and the return peak current, respectively, $E_{r p}$ is the return peak potential and $E_{1 / 2}$ is the half-wave potential. However, the published working curve applied was developed for an ITIES subjected to linear diffusion on both forward and reverse transfer processes and hence is not applicable to the present situation. Our approach was to compare the shape of the experimental $\mathrm{CV}$ for $\mathrm{RacH}^{+}$transfer to that for $\operatorname{TPrA}^{+}$transfer recorded with different switching potentials [63, 64]. Finding a shape for the model ion transfer process which match to that for $\mathrm{RacH}^{+}$, by visual comparison, allowed the $E_{1 / 2}$ for the ionised drug transfer to be determined by assuming that similar current ratios and potential ratios apply to both ions (i.e. that they have similar transfer kinetics and are not distorted by experimental variables such as cell resistance and capacitance). The $E_{1 / 2}$ of the $\mathrm{RacH}^{+}$ion was estimated in this way to be $0.9 \mathrm{~V}$. Taking into account the assumption that Walden's rule $\left(D^{o} / D^{w}=\eta^{w} / \eta^{o}\right)$ applies to the transfers of $\mathrm{RacH}^{+}$and $\mathrm{TPrA}^{+}$, the Galvani transfer potential of $\mathrm{RacH}^{+}$is obtained using Eq.(3) to be $0.29 \mathrm{~V}$ (Table 1) [58].

The formal Gibbs energy of transfer of any ionic species is expressed as [24, 44, 58]:

$\Delta_{o}^{w} \emptyset^{0^{\prime}}=\frac{\Delta G_{t r}^{0^{\prime}, w \rightarrow o}}{z F}$

where $\Delta G_{t r}^{0^{\prime}, w \rightarrow o}$ is the formal Gibbs transfer energy of ion from the aqueous (w) to the organic (o) phase. The calculated value is presented in Table 1. The formal Gibbs energy of transfer of $\mathrm{RaCH}^{+}$was $27.9 \mathrm{~kJ} \mathrm{~mol}^{-1}$ across a water | $\mathrm{DCH}$ interface. Values of $18.3 \mathrm{~kJ} \mathrm{~mol}^{-1}$ and $7.7 \mathrm{~kJ} \mathrm{~mol}^{-}$ ${ }^{1}$ have been reported previously for protonated pyridine $\left(\mathrm{PyH}^{+}\right)$transfer across a water 12 nitrophenyl octyl ether (NPOE) interface, and protonated quinidine $\left(\mathrm{QH}^{+}\right)$transfer across a water | DCE interface, respectively. 
Another important thermodynamic parameter is the partition coefficient $(\log P)$ of a given solute between two immiscible solvents. This is a measurement of its relative affinity for the two phases, and is related to the free energy of transfer of the solute between the two solvents [24, $65]$. The measurement of the ionised drug partition coefficient is vital since most drugs ( $>70 \%)$ are ionisable under physiological conditions [44]. In this case, the partition coefficient of $\mathrm{RaCH}^{+}$ between water and DCH is obtained from Eq. (5) [19, 44, 60]:

$\log P_{D C H}^{0}$ (ionised) $=-\frac{\Delta G_{t r}^{0^{\prime}, w \rightarrow o}}{2.3 R T}$

where $R$ is the gas constant $\left(R=8.31 \mathrm{~J} \mathrm{~K}^{-1} \mathrm{~mol}^{-1}\right)$ and $T$ is the temperature in kelvin. The partition coefficient of the $\mathrm{RacH}^{+}$was -4.9 (Table 1), while the value for $\mathrm{DNRH}^{+}$was -8.0 [19], both for the water | DCH system. Comparison of the partition coefficients of the neutral form of both drugs in $n$-octanol-water systems shows that the $\log P_{n-o c t}^{0}$ value for daunorubicin was higher than that for ractopamine, meaning that ractopamine is more hydrophilic, since a lower partition coefficient value indicates a more hydrophilic property [19]. A review of the electrochemical investigations made on the transfer of ionisable drugs at ITIES to determine their partition coefficients employing voltammetric methods for water | nitrobenzene (NB), water | NPOE, and water | DCE systems does not include any data for the water | DCH system [22], as this has been introduced only relatively recently [59].

\subsection{Optimisation of the LSSV parameters for the detection of $\mathrm{RacH}^{+}$}

In order to detect lower concentrations, LSSV was employed, as this entails a preconcentration step that enhances sensitivity. In the pre-concentration step, $\mathrm{RacH}^{+}$was extracted from the aqueous to the organogel phase under potential control. Then, the preconcentrated analyte was stripped out of the organogel using a voltammetric scan [21, 37]. The pre-concentration step is important in LSSV as it enables the detection of lower concentrations relative to $\mathrm{CV}$. This stripping analysis method is reported to offer greater sensitivity and lower detection limits, down to nanomolar and parts per billion levels [37]. As a result, the optimisation of LSSV parameters, namely the sweep rate, the pre-concentration potential and the preconcentration time, was explored, employing Cell 1. Voltammetric scans were conducted in the negative direction, from 1.0 to $0.4 \mathrm{~V}$.

To assess the impact of sweep rate on the results (figure not shown), the sweep rate value was varied between 5 and $100 \mathrm{mV} \mathrm{s}^{-1}$, using $100 \mu \mathrm{M} \mathrm{RacH}^{+}$. The pre-concentration potential was fixed at $1.0 \mathrm{~V}$ while the pre-concentration time was set at $60 \mathrm{~s}$. A blank LSSV was recorded 
in the absence of analyte, so that background-subtracted LSSV could be obtained by subtracting the blank response from that of the analyte. The stripping peak current was found to be linearly-dependent on the square root of the sweep rate, indicating a linear diffusioncontrolled organic phase to aqueous phase transfer process [41]. Despite this result, it was found that lower sweep rates produced a more clearly-defined peak shape, consistent with peak distortion by cell resistance and capacitance at the higher sweep rates. Consequently, all subsequent experiments employed a sweep rate of $5 \mathrm{mV} \mathrm{s}^{-1}$ since this sweep rate produced a well-defined peak shape with less sensitivity to these distortions.

The influence of the pre-concentration potential was studied by employing $20 \mu \mathrm{M} \mathrm{RacH}$ with a $60 \mathrm{~s}$ pre-concentration time, while varying the pre-concentration potential from 0.60 to $1.00 \mathrm{~V}$ in increment of $0.05 \mathrm{~V}$ (Fig. 3). From the inset graph, it can be seen that the stripping peak current only appeared when the pre-concentration potential was higher than $0.85 \mathrm{~V}$. As observed earlier by $\mathrm{CV}, \mathrm{RacH}^{+}$transfers at an applied potential very close to upper limit of the potential window. The maximum stripping peak current was observed when the preconcentration potential was $1.00 \mathrm{~V}$, thus this potential was applied for all subsequent experiments.

The influence of pre-concentration time was studied at $1.00 \mathrm{~V}$ pre-concentration potential using $100 \mu \mathrm{M} \mathrm{RacH}^{+}$, with variations in the pre-concentration time from $15 \mathrm{~s}$ to $180 \mathrm{~s}$. Over the time range of 0-1 min, the increment was $15 \mathrm{~s}$, while in the range 1-3 min, the time increment was increased to $30 \mathrm{~s}$ (Fig. 4). The stripping peak current increased as the pre-concentration time increased, eventually reaching a constant value, as illustrated in the inset graph. This effect was reported previously for the detection of propranolol [21] and oligopeptides [39] at the micro-ITIES array, and was attributed the diffusion of analyte away from the interface to the bulk organic phase during the longer pre-concentration times. Therefore, during stripping step, these analytes are not stripped back to the aqueous phase and do not contribute to the stripping peak [37]. The optimum pre-concentration time of $120 \mathrm{~s}$ was selected and applied in all subsequent experiments.

\subsection{LSSV analysis at the micro-ITIES array}

Employing all of the optimised parameters $\left(5 \mathrm{mV} \mathrm{s}^{-1}\right.$ sweep rate, $1.00 \mathrm{~V}$ pre-concentration potential, $120 \mathrm{~s}$ pre-concentration time), low concentrations of $\mathrm{RacH}^{+}$in the range $0.1-1.0 \mu \mathrm{M}$ were analysed and a calibration graph was plotted of stripping peak current versus concentration of $\mathrm{RacH}^{+}$(Fig. 5). The increase in $\mathrm{RacH}^{+}$concentration resulted in an increase of the stripping peak current, with a linear concentration dependence observed within the range 


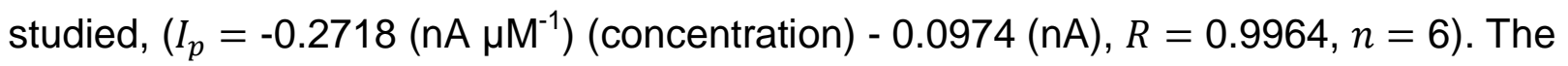
calculated limit of detection (LOD) is $0.1 \mu \mathrm{M}\left(34 \mathrm{ng} \mathrm{mL}^{-1}\right)$, based on 3 times the standard deviation of the blank $\left(3 s_{b}\right)$ [66]. This compares well with previously published values. LODs of $1.17 \mu \mathrm{M}$ (CV and electrochemical impedance spectroscopy at a modified electrode) [67], 0.06 $\mu \mathrm{M}$ (DPV at a carbon nanotube-modified glassy carbon electrode (GCE)) [6], $0.05 \mu \mathrm{M}$ (DPV at a graphene oxide-modified GCE) [13], and $0.06 \mu \mathrm{M}$ (DPV at an ordered mesoporous carbonmodified GCE) [7] have been reported for ractopamine.

\subsection{Influence of potentially interfering substances}

Possible interferences in the detection of $\mathrm{RacH}^{+}$were investigated using substances such as a sugar, ascorbic acid, metal ions, an amino acid and urea $[6,7,19,68]$. These substances were selected since they are all models of substances likely to be present in a biological sample. This study was conducted using CV. The aqueous phase of the electrochemical cell (setup as in Cell 2) was spiked with the $\mathrm{RacH}^{+}$and individual interference substances at concentrations of $0.1 \mathrm{mM}$ and $5.0 \mathrm{mM}$, respectively. The current signal for $0.1 \mathrm{mM} \mathrm{RacH}^{+}$was individually measured in the absence and presence of the interfering substances, and the current change was then determined. In addition, $\operatorname{TPrA}^{+}$was spiked to every aqueous test phase as a model ion and a potential axis reference ion. The results obtained are summarised in Fig. 6 and in Table 2.

Glucose was chosen as a model of possible sugar interference. Since it is an uncharged molecule and hence does not provide a current for transfer across the water | DCH interface, it is not expected to impact on the detection of $\mathrm{RacH}^{+}$since no ion transfer signal was detected (Fig. 6 (a)). The potential interference of ascorbic acid was also investigated, and no transfer of ascorbate was observed (Fig. 6 (b)). Ascorbic acid ( $\mathrm{p} K_{a}$ of 4.17 [19]) was de-protonated in the aqueous phase. The possible interference of metal ions such as $\mathrm{K}^{+}$and $\mathrm{Na}^{+}$were also evaluated. Metal ions, in particular $\mathrm{K}^{+}$and $\mathrm{Na}^{+}$, are expected to transfer at the positive end of the potential window, which results in a decrease of the potential window [19, 49,69]. Additions of $\mathrm{KCl}$ (Fig. 6 (c)), $\mathrm{NaCl}$ (Fig. 6 (d)) and $\mathrm{Na}_{2} \mathrm{SO}_{4}$ (Fig. 6 (e)) to the aqueous phase did alter the $\mathrm{RacH}^{+}$ion transfer signal, in agreement with previous reports [19, 69], with $\mathrm{KCl}$ having the greatest impact. Glycine was used as a model amino acid interferent and is widely reported in interference studies $[6,7,19]$. At physiological $\mathrm{pH}$, glycine is a net neutral molecule hence it should not show any ion transfer behaviour at the interface (Fig. 6 (f)) [19]. However, there was a slight increase in current at the positive end of the potential window when glycine was added. Note that although amino acids can be transferred across the ITIES [70], a low $\mathrm{pH}(\mathrm{pH} \leq 1.0)$ is 
required to ensure complete protonation of the amino acid, and an ionophore must be used to facilitate the transfer process. The possible interference of urea was also investigated (Fig. 6 (g)). Urea did not show a transfer signal at the interface, since it is a neutral compound [71]. In addition, a control experiment to assess the impact of the PBS solution on the interfering substance CVs was conducted, since all the interfering substance stock solutions were prepared in PBS solution (Fig. 6 (h)). The same injection volume as used to prepare $5.0 \mathrm{mM}$ of interfering substance was applied. The addition of PBS was observed to have a minimal impact on the interfering substance's CV.

The current changes in the presence of interfering substances (\% Relative difference, Table 2) were in the range of 6.2 to $19.2 \%$, and 0.7 to $16.1 \%$, based on the forward and reverse scan currents of $\mathrm{RacH}^{+}$, respectively. The forward current is more sensitive to the presence of potentially-interfering substances than the reverse scan. Substances not expected to interfere produced a 10\% current increase in the forward scan. For both scans, KCl (Fig. 6 (c)) demonstrated the highest current change. In all cases, the results exhibited $3 \%$ relative standard deviation (\% RSD) from repeated measurements on a single electrochemical cell $(n=$ 3). Table 2 also summarises the total variation in the $\mathrm{RaCH}^{+}$signal in the absence of potentially interfering substances (\% RSD of $15.3 \%$ and $16.9 \%$ for the forward and reverse scans, respectively), which reflects the experimental day-to-day reproducibility of the experiments.

In addition, the background current signal demonstrated \% RSD of $16.3 \%, 19.3 \%$ and 10.3 $\%$, measured at the minimum, maximum and within the 'polarisation range' (at $0.6 \mathrm{~V}$ ) potentials, respectively, based on the blank CVs shown in Figure 6. On the other hand, the $\operatorname{TPrA}^{+}$current signal demonstrated \% RSD of $15.8 \%$ and $12.7 \%$, measured at the minimum reverse peak and maximum forward current for this ion $(\sim 0.6 \mathrm{~V})$, respectively. Again, the variation in signals reflects the day-to-day reproducibility within the experiments.

Based on these observations, only potassium was seen to have a major impact on the detection of $\mathrm{RacH}^{+}$, and none of the other substances produced ion transfer peaks. Furthermore, since the reverse peak is less impacted than the forward current, use of a stripping voltammetry approach is suggested.

\subsection{Determination of $\mathrm{RacH}^{+}$in artificial serum}

The determination of $\mathrm{RacH}^{+}$in artificial serum as the aqueous phase electrolyte solution was conducted using Cell 3. In this study, two types of artificial serum solutions were prepared; the first contained no BSA, while the second contained BSA at physiological concentration. These 
solutions were utilised to investigate the possibility that BSA can impede the detection of $\mathrm{RacH}^{+}$, as reported previously for other ionised drugs at the ITIES [25, 35].

Several ways have been identified for BSA to hinder the detection process: potential window shortening, drug-protein binding $[25,72]$ or protein adsorption at the interface $[25,35]$. BSA is a water-soluble globular protein which has a net charge of $\sim-17$ at physiological $\mathrm{pH}$ (of 7.4) [36], while $\mathrm{RacH}^{+}$has a charge of +1 . These opposite charges contribute to ractopamine-albumin binding, although the binding effect will reduce through shielding from the electrolyte ions. Zhang et al. [72] reported that ractopamine bound to BSA mainly by electrostatic and hydrophobic interactions. The formation of the ractopamine-albumin complex was spontaneous and the strong interactions indicated that the drug has a long residence time in blood plasma. Additionally, BSA may adsorb to the ITIES. Collins et al. reported that BSA diminished the signal of ionised propranolol in artificial serum, although detection was still possible [25]. Vanysek and Sun demonstrated that the transfer of $\mathrm{Cs}^{+}$ion across a water | NB interface was inhibited by the adsorption of BSA on the interface [35]. Plasma proteins such as albumin have been reported to be a major source of interference in plasma measurement at the ITIES [19, 73].

$\mathrm{CV}$ of the two artificial serum matrices was carried out with the addition of $100 \mu \mathrm{M} \mathrm{RacH}^{+}$. Prior to that, a background CV was run over a wide potential range to establish the limits of the available potential window (Fig. 7 (a) and (b)). Incorporation of BSA in the artificial serum decreased the width of the potential window to $850 \mathrm{mV}$, from $950 \mathrm{mV}$ in its absence. Since BSA shortened the potential window at the upper limit (Fig. 7 (b)), the detection of ractopamine might be hindered as $\mathrm{RacH}^{+}$transfers at a very positive applied potential difference, close to the upper limit of the potential window, in the $\mathrm{LiCl}$ solution. It was observed that the $\mathrm{RacH}^{+}$transfer was possible in artificial serum without BSA. The protonated drug transferred close to the positive limit of the potential window on the forward scan, while on the reverse scan, a peak-shaped feature was obtained (Fig. 7 (c)). A calibration curve in artificial serum solution without BSA was obtained by plotting the background-subtracted current (both forward and reverse scans) versus the $\mathrm{RaCH}^{+}$concentration. The background-subtracted currents on both the forward and reverse scans increased proportionally with $\mathrm{RacH}^{+}$concentrations over the range studied (Fig. 7(c) inset). This is in agreement with the result obtained in aqueous $\mathrm{LiCl}$ electrolyte.

In contrast, no $\mathrm{RacH}^{+}$transfer was observed in artificial serum containing BSA (0.6 mM). A small current increment was observed on the forward scan, however no peak-shape feature was observed on the reverse scan (Fig. 7 (d)). Since the current signal varied linearly with the transferring analyte concentration, these results showed that the concentration of free $\mathrm{RacH}^{+}$in the aqueous phase was extremely low. This result is in agreement with previous studies which 
demonstrated that the presence of $1 \mathrm{mM} \mathrm{BSA}$ in artificial serum decreased the propranolol transfer current signal to $\sim 6.4 \mathrm{nA}$, from $\sim 9.7 \mathrm{nA}$ in its absence [25].

In addition, TPrA ${ }^{+}$was also spiked into each artificial serum solution (Fig. 7 (e) and (f)). No significant shift of the half-wave potential for the TPrA ${ }^{+}$ion was observed $\left(E_{1 / 2}\right.$ of $\left.\sim 0.52 \mathrm{~V}\right)$ [25]. However, the steady-state current for $\mathrm{TPrA}^{+}$in the presence of BSA decreased from 12.5 (no BSA present) to $8.5 \mathrm{nA}$. A similar observation was also made on the reverse scan, where the peak current decreased from $\sim 12.9$ to $\sim 7.9 \mathrm{nA}$ in the absence and presence of BSA, respectively. This indicated that BSA adsorbed at the interface and inhibited ion transfer.

The results presented in this section demonstrate that reduction of the available potential window, complexation of the $\mathrm{RacH}^{+}$by BSA and adsorption of the BSA to the liquid | liquid interface, are the possible interference mechanisms for the detection of ractopamine in serum via ion-transfer voltammetry. Hence, deproteinisation of samples is necessary for this voltammetric analysis to be viable.

\section{Conclusion}

The voltammetric behaviour of the $\beta$-agonist drug, protonated ractopamine, at a water $\mid \mathrm{DCH}$ micro-interface array was investigated. The results show that protonated ractopamine can be detected via CV and LSSV. However, this drug transfers at a very positive potential, close to the positive limit of the available potential window; nevertheless, estimation of the half-wave potential enabled determination of some thermodynamic parameters for this drug, such as the Gibbs energy of transfer and the partition coefficient. In addition, a stripping voltammetry approach was employed successfully to detect lower concentrations of the drug. The LOD was calculated to be $0.1 \mu \mathrm{M}$, which is suitable for applications to drug detection in real samples. Of a range of potentially interfering substances studied, only potassium ions were found to interfere in $\mathrm{RacH}^{+}$detection, due to its transfer at a potential close to the positive potential limit. Additionally, it was found that BSA diminished the ractopamine signal via potential window reduction, drug-protein complexation and protein adsorption at the ITIES. The results presented here indicate that voltammetry at the micro-ITIES array can be used for detection and characterisation of ionised drugs that transfer at high applied potentials but that analysis of biological samples will require deproteinisation. In the future, an improved performance, such as a lower detection limit, might be achieved with an electrochemical cell that provides a wider potential window, which will enable a more efficient pre-concentration reaction to be implemented. 


\section{Acknowledgements}

This work was supported by Curtin University and Malaysian Agricultural Research and Development Institute (MARDI), Malaysia. The authors thank Tyndall National Institute, Cork, Ireland, for the gift of the silicon microporous membranes. The authors acknowledge the use of equipment, scientific and technical assistance of the John de Laeter Centre, Curtin University which has been partially funded by the University, and by the State and Commonwealth Governments. Elaine Miller (Curtin University) is acknowledged for her assistance with SEM imaging.

\section{References}

[1] H.H. Girault, Charge transfer across liquid-liquid interfaces, in: J.O.M. Bockris (Ed.) Modern Aspects of Electrochemistry, Plenum Press, New York, 1993, pp. 1-62.

[2] P. Vanysek, Analytical applications of electrified interfaces between two immiscible solutions, Trends Anal. Chem., 12 (1993) 357-363.

[3] Z. Samec, Electrochemistry at the interface between two immiscible electrolyte solution, Pure Appl. Chem., 76 (2004) 2147-2180.

[4] H.H. Girault, Electrochemistry at liquid-liquid interfaces, in: A.J. Bard, C.G. Zoski (Eds.) Electroanalytical Chemistry: A Series of Advances, CRC Press, Boca Raton FL, 2010, pp. 1-104.

[5] D.W.M. Arrigan, G. Herzog, M.D. Scanlon, J. Strutwolf, Bioanalytical Applications of Electrochemistry at LiquidLiquid Microinterfaces, in: A.J. Bard, C.G. Zoski (Eds.) Electroanalytical Chemistry: A Series of Advances, CRC Press, Boca Raton FL, 2013, pp. 105-178.

[6] Z. Liu, Y. Zhou, Y. Wang, Q. Cheng, K. Wu, Enhanced oxidation and detection of toxic ractopamine using carbon nanotube film-modified electrode, Electrochim. Acta, 74 (2012) 139-144.

[7] X. Yang, B. Feng, P. Yang, Y. Ding, Y. Chen, J. Fei, Electrochemical determination of toxic ractopamine at an ordered mesoporous carbon modified electrode, Food Chem., 145 (2014) 619-624.

[8] M.E. Turberg, J.M. Rodewald, M.R. Coleman, Determination of ractopamine in monkey plasma and swine serum by high-performance liquid chromatography with electrochemical detection, J. Chromatogr., B, 675 (1996) 279-285.

[9] L. Shen, P. He, An electrochemical immunosensor based on agarose hydrogel films for rapid determination of ractopamine, Electrochem. Commun., 9 (2007) 657-662.

[10] J. Pleadin, N. Perši, A. Vulić, D. Milić, N. Vahčić, Determination of residual ractopamine concentrations by enzyme immunoassay in treated pig's tissues on days after withdrawal, Meat Sci. , 90 (2012) 755-758.

[11] L. He, Y. Su, Z. Zeng, Y. Liu, X. Huang, Determination of ractopamine and clenbuterol in feeds by gas chromatography-mass spectrometry, Anim. Feed Sci. Tech., 132 (2007) 316-323.

[12] E.I. Shishani, S.C. Chai, S. Jamokha, G. Aznar, M.K. Hoffman, Determination of ractopamine in animal tissues by liquid chromatography-fluorescence and liquid chromatography/tandem mass spectrometry, Anal. Chim. Acta, 483 (2003) 137-145.

[13] C. Wu, D. Sun, Q. Li, K. Wu, Electrochemical sensor for toxic ractopamine and clenbuterol based on the enhancement effect of graphene oxide, Sens. Actuators, B, 168 (2012) 178-184.

[14] W. Du, G. Zhao, Q. Fu, M. Sun, H. Zhou, C. Chang, Combined microextraction by packed sorbent and highperformance liquid chromatography-ultraviolet detection for rapid analysis of ractopamine in porcine muscle and urine samples, Food Chem., 145 (2014) 789-795. 
[15] W. Xiu-Juan, Z. Feng, D. Fei, L. Wei-Qing, C. Qing-Yu, C. Xiao-Gang, X. Cheng-Bao, Simultaneous determination of $12 \beta$-agonists in feeds by ultra-high-performance liquid chromatography-quadrupole-time-of-flight mass spectrometry, J. Chromatogr., A, 1278 (2013) 82-88.

[16] H. Wang, Y. Zhang, H. Li, B. Du, H. Ma, D. Wu, Q. Wei, A silver-palladium alloy nanoparticle-based electrochemical biosensor for simultaneous detection of ractopamine, clenbuterol and salbutamol, Biosens. Bioelectron., 49 (2013) 14-19.

[17] X. Lu, H. Zheng, X.-Q. Li, X.-X. Yuan, H. Li, L.-G. Deng, H. Zhang, W.-Z. Wang, G.-S. Yang, M. Meng, R.-M. Xi, H.Y. Aboul-Enein, Detection of ractopamine residues in pork by surface plasmon resonance-based biosensor inhibition immunoassay, Food Chem., 130 (2012) 1061-1065.

[18] J. Blanca, P. Munoz, M. Morgado, N. Mendez, A. Aranda, T. Reuvers, H. Hooghuis, Determination of clenbuterol, ractopamine and zilpaterol in liver and urine by liquid chromatography tandem mass spectrometry, Anal. Chim. Acta, 529 (2005) 199-205.

[19] J.A. Ribeiro, F. Silva, C.M. Pereira, Electrochemical study of the anticancer drug daunorubicin at a water/oil interface: Drug lipophilicity and quantification, Anal. Chem., 85 (2013) 1582-1590.

[20] J.A. Ortuno, A. Gil, C. Serna, A. Molina, Voltammetry of some catamphiphilic drugs with solvent polymeric membrane ion sensors, J. Electroanal. Chem., 605 (2007) 157-161.

[21] C.J. Collins, D.W.M. Arrigan, Ion-transfer voltammetric determination of the $\beta$-blocker propranolol in a physiological matrix at silicon membrane-based liquid/liquid microinterface arrays, Anal. Chem., 81 (2009) 23442349.

[22] H. Alemu, Voltammetry of drugs at the interface between two immiscible electrolyte solutions, Pure Appl. Chem., 76 (2004) 697-705.

[23] F. Reymond, P.-A. Carrupt, B. Testa, H.H. Girault, Charge and delocalisation effects on the lipophilicity of protonable drugs, Chem. Eur. J., 5 (1999) 39-47.

[24] G. Bouchard, P.-A. Carrupt, B. Testa, V. Gobry, H.H. Girault, Lipophilicity and solvation of anionic drugs, Chem. Eur. J., 8 (2002) 3478-3484.

[25] C.J. Collins, C. Lyons, J. Strutwolf, D.W.M. Arrigan, Serum-protein effects on the detection of the $\beta$-blocker propranolol by ion-transfer voltammetry at a micro-ITIES array, Talanta, 80 (2010) 1993-1998.

[26] P. Zhao, G. Zhu, W. Zhang, L. Zhang, Z. Liang, Y. Zhang, Study of multiple binding constants of dexamethasone with human serum albumin by capillary electrophoresis-frontal analysis and multivariate regression, Anal.

Bioanal. Chem., 393 (2009) 257-261.

[27] R. Mallik, M.J. Yoo, S. Chen, D.S. Hage, Studies of verapamil binding to human serum albumin by highperformance affinity chromatography, J. Chromatogr., B, 876 (2008) 69-75.

[28] Q. Zhang, Y. Huang, R. Zhao, G. Liu, Y. Chen, Determining binding sites of drugs on human serum albumin using FIA-QCM, Biosens. Bioelectron., 24 (2008) 48-54.

[29] Y.-J. Hu, Y. Liu, T.-Q. Sun, A.-M. Bai, J.-Q. Lu, Z.-B. Pi, Binding of anti-inflammatory drug cromolyn sodium to bovine serum albumin, Int. J. Biol. Macromol., 39 (2006) 280-285.

[30] X.M. He, D.C. Carter, Atomic structure and chemistry of human serum albumin, Nature, 358 (1992) 209-215.

[31] T.J. Su, J.R. Lu, Z.F. Cui, R.K. Thomas, Fouling of ceramic membranes by albumins under dynamic filtration conditions, J. Membr. Sci., 173 (2000) 167-178.

[32] P. Fechner, O. Bleher, M. Ewald, K. Freudenberger, D. Furin, U. Hilbig, F. Kolarov, K. Krieg, L. Leidner, G. Markovic, G. Proll, F. Pröll, S. Rau, J. Riedt, B. Schwarz, P. Weber, J. Widmaier, Size does matter! Label-free detection of small molecule-protein interaction, Anal. Bioanal. Chem., 406 (2014) 4033-4051.

[33] D.C. Carter, B. Chang, J.X. Ho, K. Keeling, Z. Krishnasami, Preliminary crystallographic studies of four crystal forms of serum albumin, Eur. J. Biochem., 226 (1994) 1049-1052.

[34] Y.-J. Hu, Y. Liu, Z.-B. Pi, S.-S. Qu, Interaction of cromolyn sodium with human serum albumin: A fluorescence quenching study, Bioorg. Med. Chem., 13 (2005) 6609-6614.

[35] P. Vanysek, Z. Sun, Bovine serum albumin adsorption on a water /nitrobenzene interface, Bioelectrochem. Bioenerg., 23 (1990) 177-194.

[36] Q. Shi, Y. Zhou, Y. Sun, Influence of pH and ionic strength on the steric mass-action model parameters around the isoelectric point of protein, Biotechnol. Progr., 21 (2005) 516-523.

[37] G. Herzog, V. Beni, Stripping voltammetry at micro-interface arrays: A review, Anal. Chim. Acta, 769 (2013) 10-21. 
[38] J.A. Ortuño, C. Rueda, Flow-injection amperometric determination of tacrine based on ion transfer across a water-plasticized polymeric membrane interface, Sensors, 7 (2007) 1185-1192.

[39] M.D. Scanlon, G. Herzog, D.W.M. Arrigan, Electrochemical detection of oligopeptides at silicon-fabricated micro-liquid/liquid interfaces, Anal. Chem., 80 (2008) 5743-5749.

[40] M.D. Scanlon, J. Strutwolf, D.W.M. Arrigan, Voltammetric behaviour of biological macromolecules at arrays of aqueous|organogel micro-interfaces, Phys. Chem. Chem. Phys., 12 (2010) 10040-10047.

[41] R. Zazpe, C. Hibert, J. O'Brien, Y.H. Lanyon, D.W.M. Arrigan, Ion-transfer voltammetry at silicon membranebased arrays of micro-liquid-liquid interfaces, Lab Chip, 7 (2007) 1732-1737.

[42] M. Cretin, L. Alerm, J. Bartroli, P. Fabry, Lithium determination in artificial serum using flow injection systems with a selective solid-state tubular electrode based on NASICON membranes, Anal. Chim. Acta, 350 (1997) 7-14.

[43] S. Makarychev-Mikhailov, A. Shvarev, E. Bakker, Calcium pulstrodes with 10-fold enhanced sensitivity for measurements in the physiological concentration range, Anal. Chem., 78 (2006) 2744-2751.

[44] H.-T. Lam, C.M. Pereira, C. Roussel, P.-A. Carrupt, H.H. Girault, Immobilized pH gradient gel cell to study the pH dependence of drug lipophilicity, Anal. Chem., 78 (2006) 1503-1508.

[45] J. Strutwolf, M.D. Scanlon, D.W.M. Arrigan, Electrochemical ion transfer across liquid/liquid interfaces confined within solid-state micropore arrays - Simulations and experiments, Analyst, 134 (2009) 148-158.

[46] T.J. Davies, R.G. Compton, The cyclic and linear sweep voltammetry of regular and random arrays of microdisc electrodes: Theory, J. Electroanal. Chem., 585 (2005) 63-82.

[47] Y. Saito, A theoretical study on the diffusion current at the stationary electrodes of circular and narrow band types, Rev. Polarog., 15 (1968) 177-187.

[48] M. Sairi, J. Strutwolf, R.A. Mitchell, D.S. Silvester, D.W.M. Arrigan, Chronoamperometric response at nanoscale liquid-liquid interface arrays, Electrochim. Acta, 101 (2013) 177-185.

[49] C.J. Collins, A. Berduque, D.W.M. Arrigan, Electrochemically modulated liquid-liquid extraction of ionized drugs under physiological conditions, Anal. Chem., 80 (2008) 8102-8108.

[50] K.B. Oldham, Edge effects in semi-infinite diffusion, J. Electroanal. Chem., 122 (1981) 1-17.

[51] J. Heinze, Ultramicroelectrodes in electrochemistry, Angew. Chem. Int. Ed. Engl., 32 (1993) 1268-1288.

[52] M.S.M. Quintino, L. Angnes, Bia-amperometric quantification of salbutamol in pharmaceutical products, Talanta 62 (2004) 231-236.

[53] G. Wei, W. Lu, J. Zheng, Diffusion behaviors of drugs in thermosensitive in situ gels, Acta Pharmaceut. Sin., 39 (2004) 232-235.

[54] E.S. Ferreira, A. Garau, V. Lippolis, C.M. Pereira, F. Silva, Electrochemistry of 2, 8-dithia [9],(2, 9)-1, 10phenanthrolinophane (L) at the polarized water/1, 2-dichloroethane interface: Evaluation of the complexation properties towards transition and post-transition metal ions, J. Electroanal. Chem., 587 (2006) 155-160.

[55] F. Reymond, V. Chopineaux-Courtois, G. Steyaert, G. Bouchard, P.-A. Carrupt, B. Testa, H.H. Girault, Ionic partition diagrams of ionisable drugs: $\mathrm{pH}$-lipophilicity profiles, transfer mechanisms and charge effects on solvation, J. Electroanal. Chem., 462 (1999) 235-250.

[56] F. Reymond, G. Steyaert, P.-A. Carrupt, B. Testa, H.H. Girault, Mechanism of transfer of a basic drug across the water/1,2-dichloroethane interface: The case of quinidine, Helv. Chim. Acta, 79 (1996) 101-117.

[57] G. Bouchard, P.-A. Carrupt, B. Testa, V. Gobry, H.H. Girault, The apparent lipophilicity of quaternary ammonium ions is influenced by galvani potential difference, not ion-pairing: A cyclic voltammetry study, Pharm. Res., 18 (2001) 702-708.

[58] M.D. Osborne, H.H. Girault, Amperometric detection of the ammonium ion by facilitated ion transfer across the interface between 2 immiscible electrolyte solutions, Electroanal., 7 (1995) 425-434.

[59] H. Katano, M. Senda, Voltammetry at 1, 6-dichlorohexane' water interface, Anal. Sci., 17 (2001) 1027-1029.

[60] R. Gulaboski, M.N.D.S. Cordeiro, N. Milhazes, J. Garrido, F. Borges, M. Jorge, C.M. Pereira, I. Bogeski, A.H.

Morales, B. Naumoski, A.F. Silva, Evaluation of the lipophilic properties of opioids, amphetamine-like drugs, and metabolites through electrochemical studies at the interface between two immiscible solutions, Anal. Biochem., 361 (2007) 236-243.

[61] Y. Shao, A.A. Stewart, H.H. Girault, Determination of the half-wave potential of the species limiting the potential window. Measurement of gibbs transfer energies at the water/1,2-dichloroethane interface, J. Chem. Soc., Faraday Trans., 87 (1991) 2593-2597. 
[62] M.H.M. Cacote, C.M. Pereira, L. Tomaszewski, H.H. Girault, F. Silva, Ag+ transfer across the water/1,2dichloroethane interface facilitated by complex formation with tetraphenylborate derivatives, Electrochim. Acta, 49 (2004) 263-270.

[63] Z. Samec, V. Marecek, M.P. Colombini, Standard Gibbs energies of transfer of alkali metal cations from water to 1,2-dichloroethane, J. Electroanal. Chem., 257 (1988) 147-154.

[64] A.-K. Kontturi, K. Kontturi, L. Murtomaki, D.J. Schiffrin, Use of convolution voltammetry for the determination of single-ion Gibbs energies of transfer, J. Chem. Soc. Faraday Trans., 86 (1990) 819-822.

[65] T. Nogrady, Medicinal Chemistry: A Biochemical Approach, 2nd ed., Oxford University Press, Inc., New York, 1988.

[66] J.C. Miller, J.N. Miller, Statistics for Analytical Chemistry, 2nd ed., Ellis Horwood Limited, England, 1988. [67] L.-J. Kong, M.-F. Pan, G.-Z. Fang, X.-I. He, Y.-k. Yang, J. Dai, S. Wang, Molecularly imprinted quartz crystal microbalance sensor based on poly(o-aminothiophenol) membrane and Au nanoparticles for ractopamine determination, Biosens. Bioelectron., 51 (2014) 286-292.

[68] J. Duan, D. He, W. Wang, Y. Liu, H. Wu, Y. Wang, M. Fu, S. Li, The fabrication of nanochain structure of gold nanoparticles and its application in ractopamine sensing, Talanta, 115 (2013) 992-998.

[69] H. Katano, H. Tatsumi, M. Senda, Ion-transfer voltammetry at 1,6-dichlorohexane / water and 1,4dichlorobutane / water interfaces, Talanta, 63 (2004) 185-193.

[70] Y. Chen, Y. Yuan, M. Zhang, F. Li, P. Sun, Z. Gao, Y. Shao, Systematic study of the transfer of amino acids across the water/1,2-dichloroethane interface facilitated by dibenzo-18-crown-6, Sci. China, Ser. B, 47 (2004) 2433.

[71] M.D. Osborne, H.H. Girault, The liquid-liquid micro interface for the amperometric detection of urea, Electroanal., 7 (1995) 714-721.

[72] Q. Zhang, Y. Ni, S. Kokot, Molecular spectroscopic studies on the interaction between ractopamine and bovine serum albumin, J. Pharm. Biomed. Anal., 52 (2010) 280-288.

[73] J. Guo, Y. Yuan, S. Amemiya, Voltammetric detection of heparin at polarized blood plasma/1,2dichloroethane interfaces, Anal. Chem., 77 (2005) 5711-5719.

[74] National Institutes of Health, Hazardous Substances Data Bank: Ractopamine, http://toxnet.nlm.nih.gov (23/03/2014). 

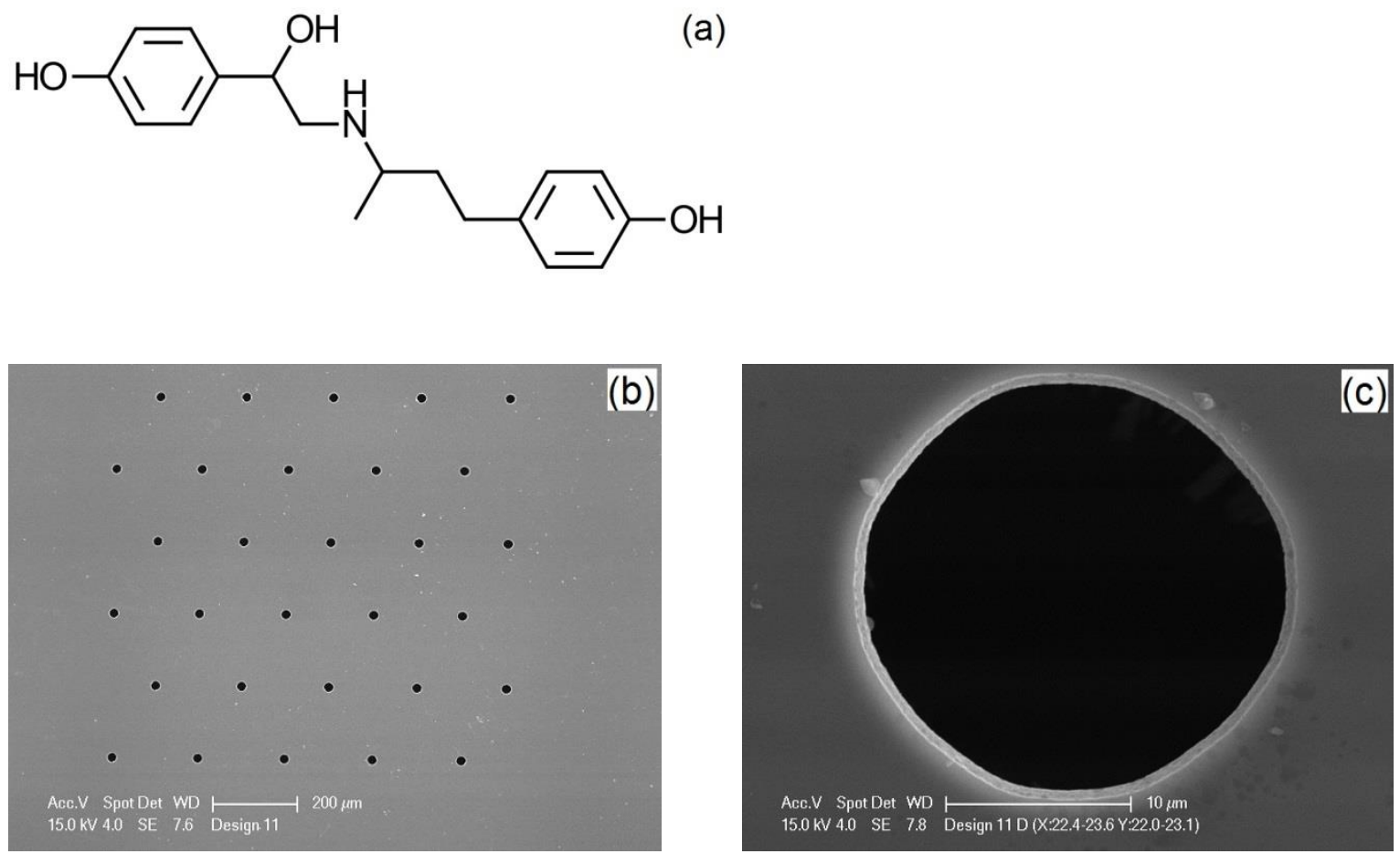

Fig. 1. (a) Molecular structure of ractopamine (b) SEM image of the full micropore array silicon membrane, and (c) SEM of a single micropore within the array 

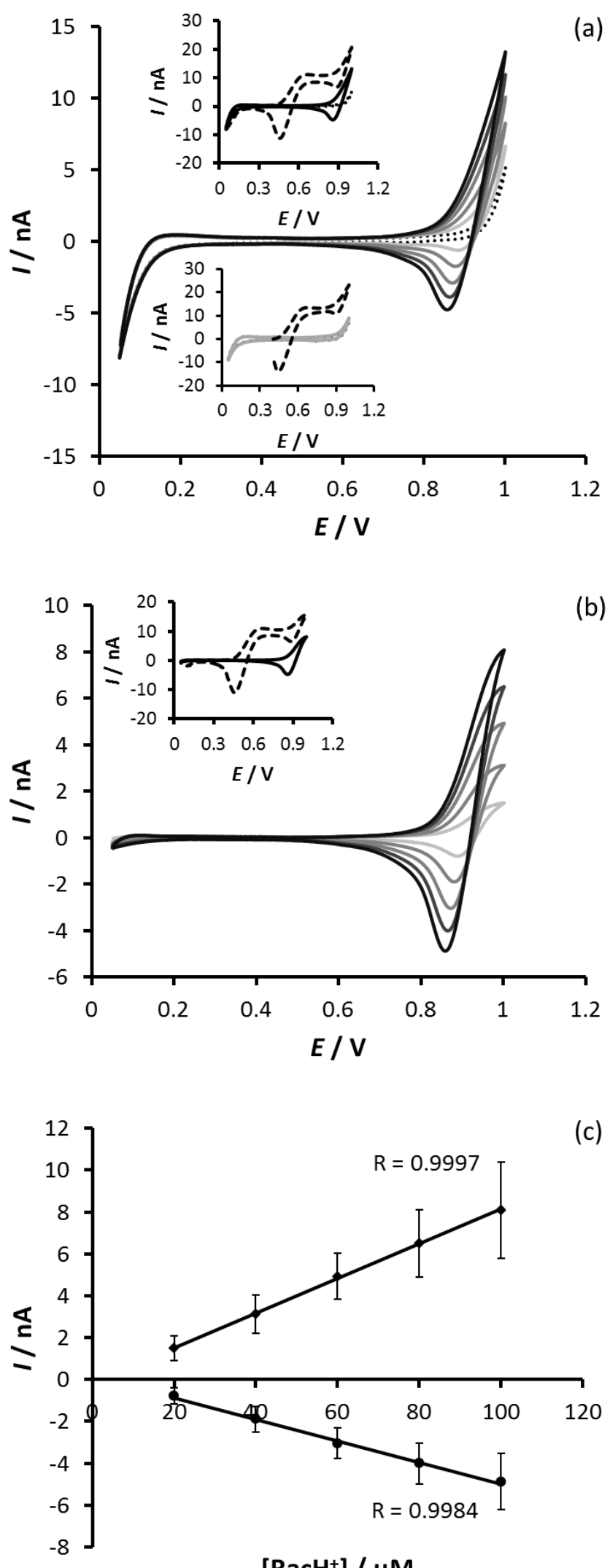

$\left[\mathrm{RacH}^{+}\right] / \mu \mathrm{M}$

Fig. 2. Cyclic voltammograms of 20 (light gray) to $100 \mu \mathrm{M}$ (black) $\mathrm{RacH}^{+}$transfer, in increment of $20 \mu \mathrm{M}$ (a) and its corresponding background-subtracted CV (b) at $5 \mathrm{mV} \mathrm{s}^{-1}$ sweep rate. Inset (a - upper) and (b): voltammograms of blank (dotted line) and $100 \mu \mathrm{M} \mathrm{RacH}^{+}$with (dashed line) and without (solid black line) the addition of $\mathrm{TPrA}^{+}$. Inset (a - lower) is a control experiment with $100 \mu \mathrm{M} \mathrm{MeOH}$ (solid gray line) added to the aqueous phase (c) The corresponding calibration curve of the maximum currents (forward scan) and peak currents (reverse scan) against $\mathrm{RacH}^{+}$concentrations 


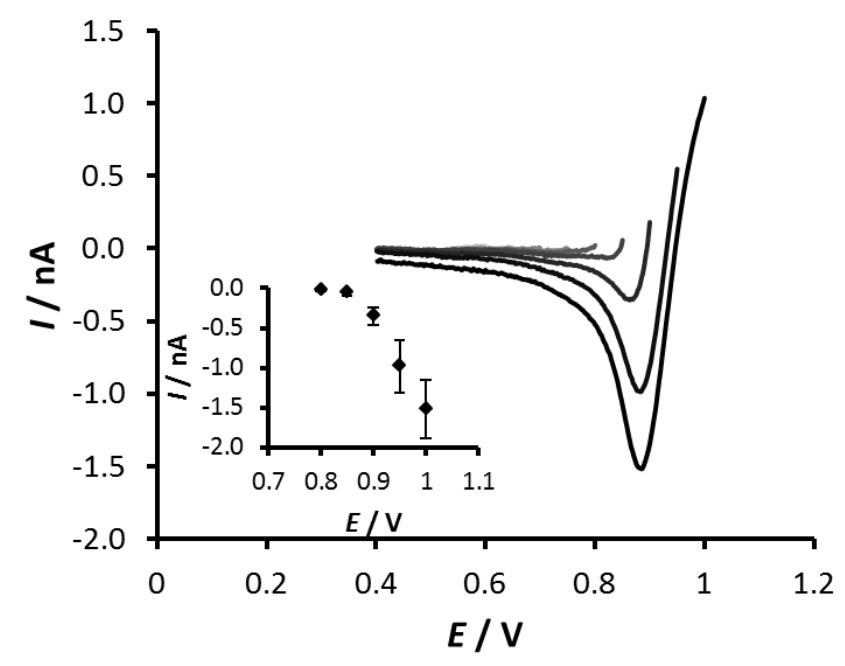

Fig. 3. Influence of pre-concentration potentials from $0.6 \mathrm{~V}$ (light gray) to $1.0 \mathrm{~V}$ (black) in increment of $0.05 \mathrm{~V}$ on the LSSV (background-subtracted) of $20 \mu \mathrm{M} \mathrm{RacH}{ }^{+}$. The pre-concentration time and sweep rate were fixed at $60 \mathrm{~s}$ and $5 \mathrm{mV} \mathrm{s}^{-1}$, respectively. Inset: graph of current at selected pre-concentration potentials of $0.80,0.85,0.90,0.95$ and $1.00 \mathrm{~V}$ 


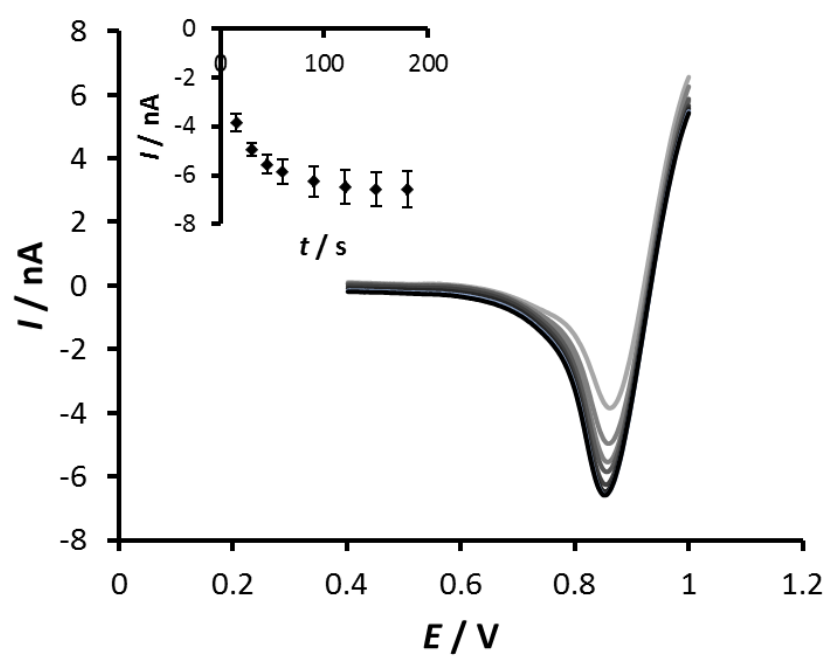

Fig. 4. Influence of pre-concentration times on the LSSV (background-subtracted) of $100 \mu \mathrm{M} \mathrm{RacH}^{+}$. The pre-concentration potential and sweep rate were fixed at $1.0 \mathrm{~V}$ and $5 \mathrm{mV} \mathrm{s}^{-1}$, respectively. LSSV response of 15 (light gray), 30, 45, 60, 90, 120, 150 and $180 \mathrm{~s}$ (black) pre-concentration times. Inset: calibration graph of peak current versus pre-concentration times 


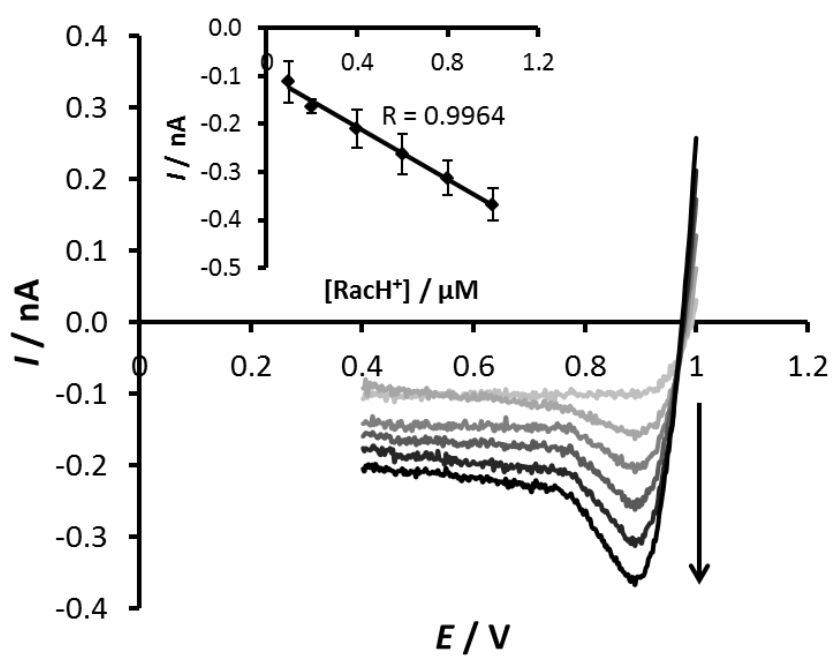

Fig. 5. Background-subtracted LSSV scans of increasing $\mathrm{RacH}^{+}$concentrations in the aqueous phase (indicated by arrow) at the micro-ITIES arrays at $5 \mathrm{mV} \mathrm{s}^{-1}$ sweep rate. LSSV response of 0.1 (light gray), $0.2,0.4,0.6,0.8$ and $1.0 \mu \mathrm{M}$ (black) drug concentrations. Inset is the calibration curve of stripping peak current versus concentration 

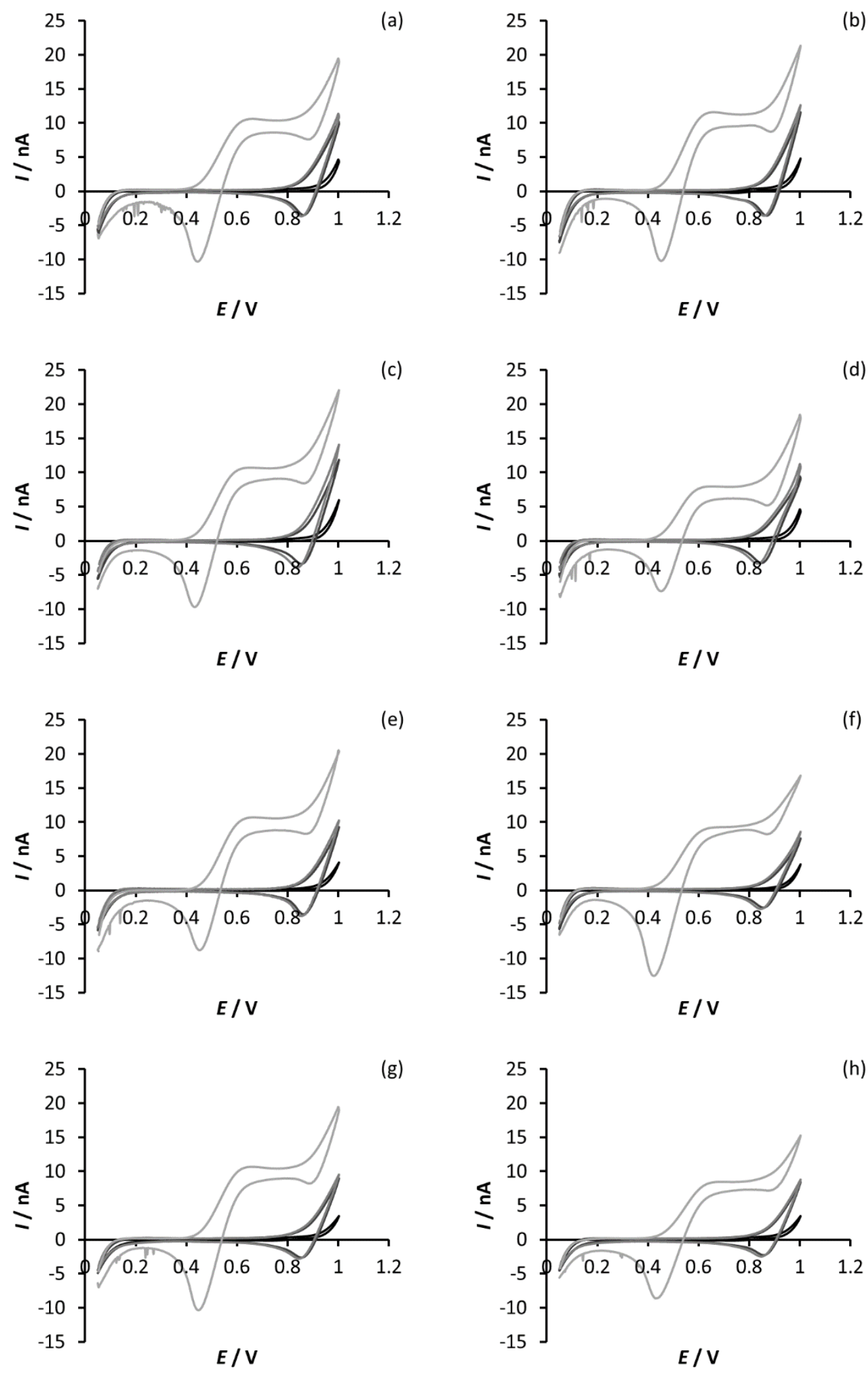

Fig. 6. Electrochemistry of the individual interfering substances at the micro-ITIES arrays. Cyclic voltammograms of the blank aqueous phase solution (10 $\mathrm{mM} \mathrm{LiCl}$ (black line), the aqueous phase spiked with $100 \mu \mathrm{M} \mathrm{RacH}{ }^{+}$(dark gray line), the aqueous phase spiked with $100 \mu \mathrm{M} \mathrm{RacH}{ }^{+}$and the interfering substances (medium gray line), and the aqueous phase spiked with $100 \mu \mathrm{M} \mathrm{RacH}{ }^{+}$, the interfering substances and $100 \mu \mathrm{M} \mathrm{TPrA}^{+}$(light gray line). The interfering substances studied: (a) Dglucose (b) L-ascorbic acid (c) $\mathrm{KCl}$ (d) $\mathrm{NaCl}$ (e) $\mathrm{Na}_{2} \mathrm{SO}_{4}$ (f) glycine (g) urea, and (h) PBS solution in the absence of the interfering substance (control). The interfering substance concentration in all cases was $5.0 \mathrm{mM}$, and run at $5 \mathrm{mV} \mathrm{s}^{-1}$ sweep rate 

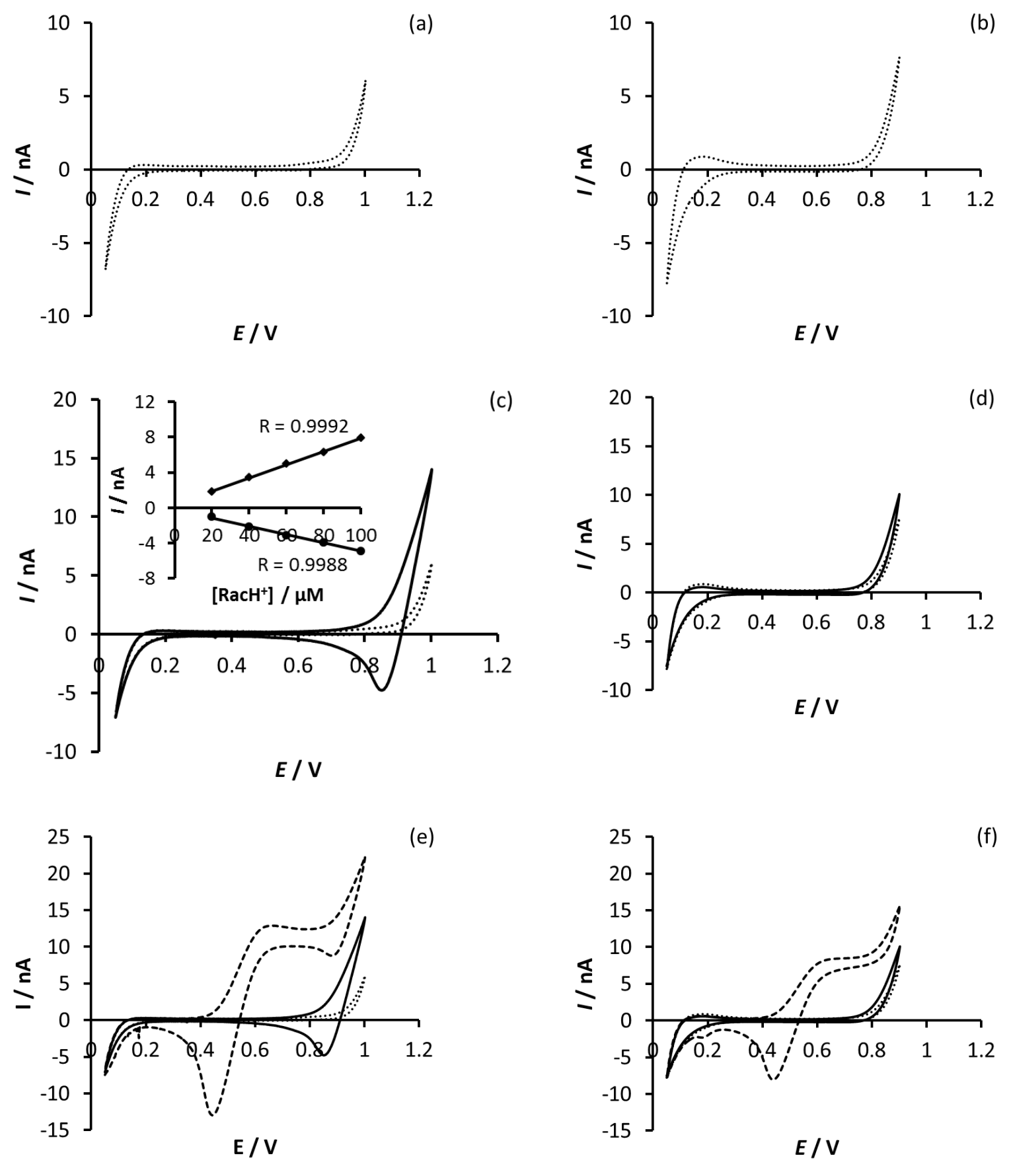

Fig. 7. Cyclic voltammetry at the micro-ITIES array of an artificial serum solution in the aqueous phase ((a) and (b)), $100 \mu \mathrm{M} \mathrm{RacH}{ }^{+}$in an artificial serum solution ((c) and (d)), and an artificial serum solution of $100 \mu \mathrm{M} \mathrm{TPrA}{ }^{+}$and $100 \mu \mathrm{M} \mathrm{RacH}{ }^{+}((\mathrm{e})$ and (f)). Figures (a), (c) and (e) represent cyclic voltammetry of an artificial serum without BSA, while figure (b), (d) and (f) represent cyclic voltammetry in the presence of $0.6 \mathrm{mM}$ BSA. Sweep rate applied was $5 \mathrm{mV} \mathrm{s}^{-1}$. Inset in (c) is the corresponding calibration curve obtained for $\mathrm{RacH}^{+}$transfer on the forward and reverse scans 
Table 1

Thermodynamic data for the transfer of cationic $\beta$-agonist drug, protonated ractopamine $\left(\mathrm{RacH}^{+}\right)$at the micro- water | DCH interface arrays

\begin{tabular}{ll}
\hline Parameter & Value \\
\hline $\mathrm{p} K_{a}$ & $9.4^{\mathrm{a}}$ \\
$\Delta_{0}^{w} \emptyset^{0^{\prime}}$ & $\sim 0.29 \mathrm{~V}$ (in DCH) \\
$\Delta G_{t r}^{0^{\prime}, w \rightarrow D C H}$ & $27.88 \mathrm{~kJ} \mathrm{~mol}^{-1}$ \\
$\log P_{D C H}^{0}$ (ionised) & -4.89 \\
$\log P_{n-o c t}^{0}$ & $2.4^{\mathrm{b}}$
\end{tabular}

a Data obtained from reference [8]
${ }^{\mathrm{b}}$ Data obtained from reference [74] 


\section{Table 2}

Influence of potentially interfering substances on the detection of protonated ractopamine $\left(\mathrm{RacH}^{+}\right)$at the micro- water | DCH interface array. The concentration of $\mathrm{RacH}^{+}$and interfering substance in all cases were $0.1 \mathrm{mM}$ and $5.0 \mathrm{mM}$, respectively. In the forward scan, the current was measured at the end of the scan, while in the reverse scan the minimum peak current was selected.

\begin{tabular}{|c|c|c|c|c|c|c|}
\hline \multirow[t]{2}{*}{ Interfering substance } & \multicolumn{3}{|c|}{ Forward scan } & \multicolumn{3}{|c|}{ Reverse scan } \\
\hline & $\begin{array}{l}I_{R_{R c H^{+}}} / \mathbf{n A} \\
(\mathbf{\pm} \mathbf{s} ; \mathbf{n}=\mathbf{3})\end{array}$ & $\begin{array}{l}I_{\left(\text {RacH }^{+}+\text {Interferent }\right)} \\
\text { / } \mathbf{n A}(\mathbf{\pm} \mathbf{s} ; \mathbf{n}=\mathbf{3})\end{array}$ & $\begin{array}{l}\text { Relative } \\
\text { difference } \\
(\%)^{a}\end{array}$ & $\begin{array}{l}I_{R_{a c H^{+}}} / \mathbf{n A} \\
(\mathbf{\pm} \mathbf{s} ; \mathbf{n}=\mathbf{3})\end{array}$ & $\begin{array}{l}I_{\left(\text {RacH }^{+}+\text {Interferent }\right)} \\
/ \mathbf{n A}(\mathbf{\pm} \mathbf{s} ; \mathbf{n}=\mathbf{3})\end{array}$ & $\begin{array}{l}\text { Relative } \\
\text { difference } \\
(\%)^{a}\end{array}$ \\
\hline Glucose & $9.9 \pm 0.17$ & $10.9 \pm 0.10$ & 10.3 & $3.5 \pm 0.09$ & $3.7 \pm 0.03$ & 6.0 \\
\hline Ascorbic acid & $11.6 \pm 0.12$ & $12.6 \pm 0.13$ & 9.2 & $3.5 \pm 0.05$ & $3.6 \pm 0.02$ & 0.7 \\
\hline $\mathrm{KCl}$ & $11.9 \pm 0.07$ & $14.1 \pm 0.07$ & 19.2 & $3.4 \pm 0.05$ & $3.9 \pm 0.01$ & 16.1 \\
\hline $\mathrm{NaCl}$ & $9.1 \pm 0.10$ & $10.8 \pm 0.04$ & 18.9 & $3.2 \pm 0.04$ & $3.3 \pm 0.01$ & 3.4 \\
\hline $\mathrm{Na}_{2} \mathrm{SO}_{4}$ & $9.3 \pm 0.16$ & $10.3 \pm 0.07$ & 10.7 & $3.5 \pm 0.06$ & $3.8 \pm 0.02$ & 7.6 \\
\hline Glycine & $7.6 \pm 0.08$ & $8.6 \pm 0.01$ & 13.1 & $2.5 \pm 0.06$ & $2.7 \pm 0.03$ & 8.8 \\
\hline Urea & $9.0 \pm 0.10$ & $9.5 \pm 0.08$ & 6.2 & $2.6 \pm 0.08$ & $2.8 \pm 0.05$ & 6.1 \\
\hline PBS & $8.4 \pm 0.05$ & $8.8 \pm 0.03$ & 4.4 & $2.3 \pm 0.05$ & $2.5 \pm 0.03$ & 9.6 \\
\hline Mean $( \pm s ; n=8)$ & $9.6 \pm 1.47$ & - & - & $3.1 \pm 0.52$ & - & - \\
\hline
\end{tabular}

$\mathrm{S}=$ standard deviation

${ }^{\text {a }}$ Relative difference $(\%)=\frac{I_{\left(\text {RacH }^{+}+\text {Interferent }\right)}-I_{\text {RacH }^{+}}}{I_{\text {RacH }^{+}}} \times 100 \%$ 